\title{
Síndrome hipereosinofílico con eritrodermia
}

\section{Hypereosinophilic syndrome with erythrodermia}

\author{
Héctor Huayhua-Guevara ', \\ Miguel A. Vargas-Cruz ${ }^{2}$ y \\ César A. Chian-García ${ }^{3}$
}

Huayhua-Guevara H, Vargas-Cruz M.A y Chian-García C.A. Síndrome hipereosinofílico con eritrodermia. Rev Soc Peru Med Interna. 2020;33(I):25-30.

https://doi.org/10.36393/spmi.v33i1.507 /

\begin{abstract}
RESUMEN
Varón de 77 años de edad, con antecedentes de insuficiencia cardiaca y fibrilación auricular recibiendo warfarina, hipotiroidismo, diabetes mellitus e hiperuricemia, con historia de un año de lesiones dérmicas eritematosas y descamativas en el tronco, pruriginosas y con moderada eosinofilia recurrente. Después de descartarse causas alérgicas, parasitarias, autoinmunes y neoplásicas, se hizo el diagnóstico de síndrome hipereosinofilico idiopático. Recibió tratamiento con prednisona e hidroxiurea, consiguiéndose una remisión completa de la eosinofilia y mejoría progresiva de las lesiones dérmicas.
\end{abstract}

Palabras claves: Eosinofilia, hipereosinofilia, piel, prednisona.

\section{ABSTRACT}

A 77-year-old male, with a history of heart failure and atrial fibrillation receiving warfarin, hypothyroidism, diabetes mellitus and hyperuricaemia, with a one-year history of erythematous and desquamative skin lesions in the trunk, pruritic and moderate recurrent eosinophilia. After allergic, parasitic, autoimmune and neoplastic causes were ruled out, the diagnosis of idiopathic hypereosinophilic syndrome was done. He was treated with prednisone and hydroxyurea, resulting in complete remission of eosinophilia and progressive improvement of dermal lesions.

Keywords: Eosinophilia, hypereosinophilia, skin, prednisone.

\section{INTRODUCCIÓN}

El síndrome hipereosinofílico ( $\mathrm{SH}$ ) es una enfermedad caracterizado por eosinofilia $>1500$ células $/ \mu \mathrm{L}$, persistente, documentada en dos ocasiones por espacio

I Médico residente de Nefrología. Facultad de Medicina, Universidad Nacional Mayor de San Marcos. Hospital Nacional Arzobispo Loayza.

2 Médico internista. Facultad de Medicina, Universidad Nacional Mayor de San Marcos. Hospital Nacional Arzobispo Loayza.

3 Médico patólogo. Facultad de Medicina, Universidad Peruana Cayetano Heredia. Hospital Nacional Arzobispo Loayza. de un mes y/o confirmación patológica de hipereosinofilia tisular, evidencia de daño o disfunción de órgano mediada por eosinófilos y exclusión de otras causas potenciales que podrían explicar dicha eosinofilia. (1)

El SH es raro, se desconoce la prevalencia real, estimándose 0,36-6,3 por cada 100000 habitantes en Estados Unidos. (2) La mayoría de los pacientes se diagnostican a la edad de los 20 a 50 años, pero en niños también pueden presentarse y la forma frecuente es primaria clonal tipo mieloide. $(3,4)$ En nuestro país son escasos los reportes de esta entidad. Presentamos el caso de un paciente con prurito persistente y eritrodermia, con eosinofilia moderada y recurrente, iniciando el abordaje clínico con el estudio diferencial de eosinofilia.

\section{PRESENTACIÓN DEL CASO}

Paciente varón de 77 años, procedente de Yunguyo-Puno con antecedente de haber trabajado 12 años en una mina a partir de los 20 años de edad, con antecedentes de falla cardiaca crónica de hace 20 años y fibrilación auricular de hace 15 años en terapia con warfarina; hipotiroidismo de hace 15 años; diabetes mellitus sin tratamiento más hiperuricemia; operado de varices en la pierna derecha hace 30 años y de hernia umbilical hace 10 años. Realizó 
un viaje a Brasil (Porto Alegre) un año atrás por espacio de tres meses.

Ingresó con un tiempo de enfermedad de un año que inició con prurito en las manos de manera intermitente, que se extendió a los brazos y el rostro, de intensidad moderada por lo que acudió a un consultorio privado de dermatología donde le prescribieron cremas sin mejoría significativa. Hace seis meses, el prurito se generalizó con predominio del dorso. Hace dos meses notó edema y eritema en la cara por lo que fue hospitalizado por dos semanas, recibiendo un curso de prednisona $50 \mathrm{mg}$ /día y al alta con $20 \mathrm{mg} /$ día, mejorando el prurito pero, parcialmente, las lesiones dérmicas.

Quince días antes de su ingreso a nuestro hospital, reinició el prurito generalizado y disnea de esfuerzos a 100 y 200 metros) y ortopnea leve por lo que acudió a consultorio externo de oncología quienes indicaron su hospitalización. El examen físico de ingreso: lúcido, piel difusamente acartonada, hiperpigmentada, gruesa con lesiones eritematosas y descamativas generalizadas, liquenificadas (Figuras 1 y 2). Edema duro y frío de los miembros inferiores que dejan fóvea. Macroglosia y en el cuello se palpaba una adenopatía submandibular derecha de 1 × 2 cm, indurada y móvil. Aparato cardiovascular: ruidos cardiacos arrítmicos, de regular intensidad y frecuencia normal con pulso deficitario, no soplos. Tórax y pulmones: murmullo vesicular normal, no ruidos agregados. Abdomen globuloso, timpánico, blando, depresible, no doloroso, no visceromegalia. Neurológico: orientado en tiempo, espacio y persona, no déficit motor ni sensitivo, no signos meníngeos ni de focalización.

Exámenes previos al ingreso. Radiografía de tórax: cardiomegalia global, ICT de 0,6. TAC abdominal y pélvica: pequeños quistes en el riñón izquierdo.

Biopsia de piel (tres meses antes del ingreso): dermatitis crónica espongiótica con numerosos eosinófilos, sin linfocitos intraepidérmicos ni atípicos, concluyendo como eccema crónico. Biopsia de ganglio inguinal (una semana antes del ingreso): abundantes linfocitos, algunos de ellos atípicos, no concluyente. Biopsia de piel (una semana ante del ingreso): dermis con moderado infiltrado de linfocitos pequeños y moderada cantidad de eosinófilos, hasta 25 por campo, sugerente de reacción adversa a medicamentos $\mathrm{u}$ otro agente alérgico.

En los hemogramas previos a su ingreso se evidenció eosinofilia persistente (Cuadro 1). En los exámenes auxiliares de ingreso a nuestro hospital: $\mathrm{Hb} 13,20 \mathrm{~g} / \mathrm{dl}$, leucocitos $12200 / \mathrm{mm}^{3}$ (abastonados 4\%, neutrófilos 36\%, eosinófilos $32 \%$, linfocitos $20 \%$, monocitos $8 \%$ ), plaquetas $304000 / \mathrm{mm}^{3}$; bioquímica sanguínea normal. TSH 1,75 $\mathrm{UI} / \mathrm{ml}$, T4 libre $0,86 \mathrm{ng} / \mathrm{dl}$. PCR $16,49 \mathrm{mg} / \mathrm{dl}$, VSG 45 $\mathrm{mm} /$ hora. Calcio 8,3 mg/dl, DHL $498 \mathrm{U} / 1$. INR 1,79 (con anticoagulación), TP 19,4 seg.

Estudios serológicos: VHB, VHC, VEB, VIH, HTLV I-II, brucella, tíficos y paratíficos, todos negativos

Examen parasitológico seriado: negativos. FAST 2 Fasciola (anticuerpos) 0,09 (no infección). IgE>2 500 UI/ml. Anticuerpos contra Toxocara canis (IgM) 0,1 (negativo).

Biopsia de piel: Epidermis con paraqueratosis, hiperplasia psoariasiforme irregular y espongiosis; en dermis, marcado infiltrado eosinófilo perivascular e intersticial que llega hasta el tejido celular subcutáneo acompañado de infiltrado mononuclear (Figuras 3 y 4).

Biopsia de ganglio cervical: ganglio linfático infiltrado por sábanas de histiocitos epitelioides con depósitos de pigmento más algunos eosinófilos y numerosas células plasmáticas, hallazgos compatibles con linfadenopatía dermatopática (Figuras 5 y 6 ).

Citometría de flujo (Aspirado de médula ósea): células neoplásicas $0 \%$, blastos $1,14 \%$, neutrófilos $65,01 \%$, monocitos 3,49\%, basófilos $0,15 \%$, eosinófilos $10,04 \%$, linfocitos T 4,97\%, CD4/CD8 0,95, linfocitos B 0,22\%, kappa/lambda 1,37\%, progenitores B $0,15 \%$, NK 1,14\%, linfocitos TCR g/d 0,31\%, plasmocitos $0,47 \%$, eritroide $12,91 \%$.

Estudio genético para la aberración del gen FIP1L1/ PDGFRA mediante el método molecular RT-PCR convencional: negativo.
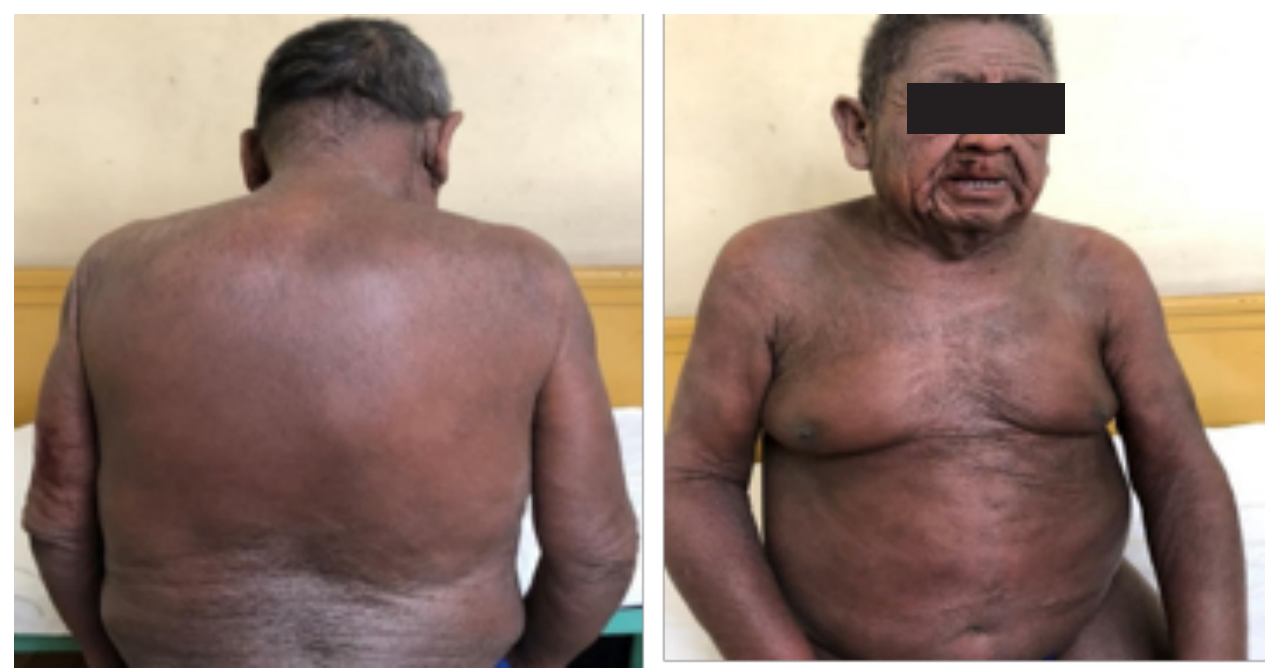

Figuras 1 y 2. Eritrodermia y síndrome hipereosinofílico. 


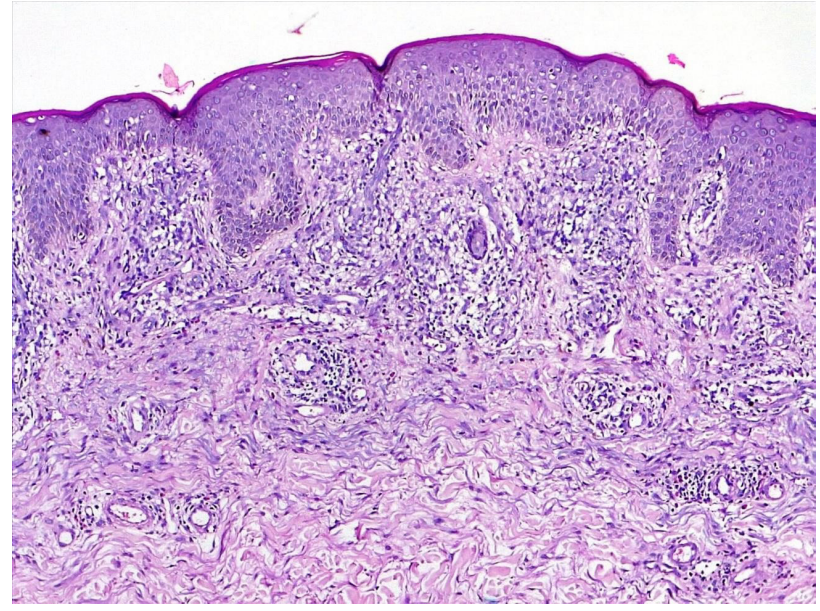

Figura 3. Biopsia de Piel. HE10X. Se observa hiperplasia epidérmica irregular e infiltrado inflamatorio perivascular superficial.

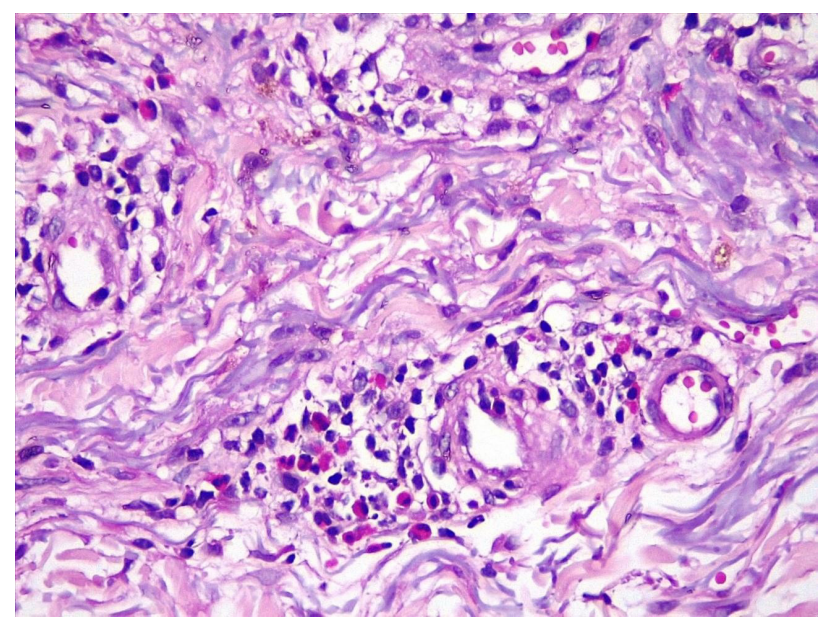

Figura 4. Biopsia de Piel. HE40X. Se observa infiltrado dérmico con numerosos eosinófilos.

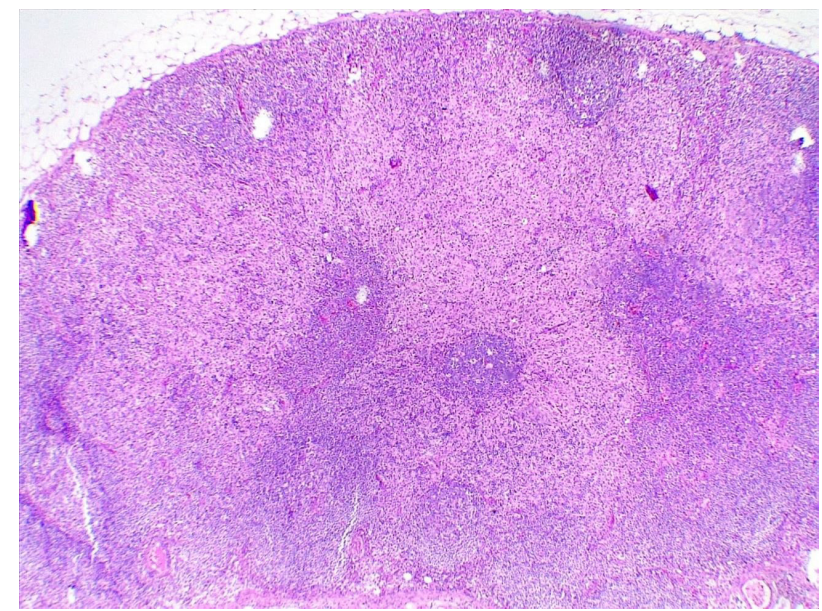

Figura 5. Biopsia de Ganglio. HE10X. Se observa marcada expansión sinusoidal (áreas de tonalidad pálida que ocupan la mayor parte del tejido) con pequeño remanente de folículos linfoides primarios (áreas más oscuras).

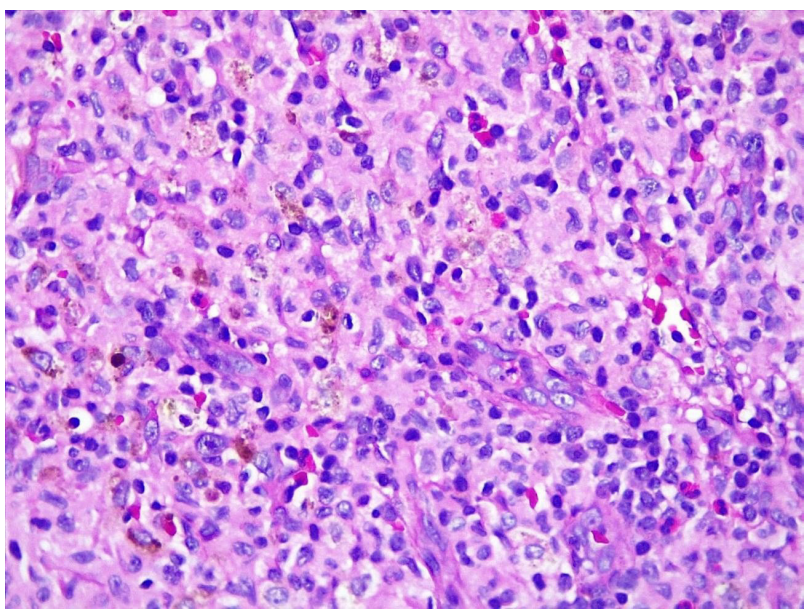

Figura 6. Biopsia de Ganglio. HE40X. Se observa numerosos histiocitos (células de citoplasma amplio y claro), eosinófilos y depósitos de pigmento marrón, de apariencia melánica.

Con el diagnóstico de $\mathrm{SH}$ se inició terapia con corticoide (prednisona $1 \mathrm{mg} / \mathrm{k} / \mathrm{d})$ e hidroxiúrea $(10 \mathrm{mg} / \mathrm{k} / \mathrm{d})$, presentando mejoría clínica y remisión completa de la eosinofilia (ausencia de eosinófilos) en un periodo menor a 5 días. Al mes, el compromiso dérmico presentó gran mejoría sin descamación y disminución notable del engrosamiento dérmico, así como la desaparición del prurito.

DISCUSIÓN

El proceso de diagnóstico de un paciente con eosinofilia empieza por confirmar la certeza del aumento de los eosinófilos, valorar el recuento absoluto de los mismos para clasificarlos según su severidad en leve (500-1 500), moderado (1 500-5 000) y severo (>5 000), así como el contexto epidemiológico y clínico. Cuadro 2.

Iniciamos un enfoque diagnóstico de causas asociadas a eosinofilia. Entre los diagnósticos principales a tenerse en cuenta teníamos la etiología neoplásica y la secundaria a parasitosis por el antecedente epidemiológico de provenir de una zona endémica de fasciolasis, la región de Yunguyo. $(7,8)$

Nuestro paciente se presentó con prurito que se reporta de manera frecuente en el SH pero la eritrodermia generalizada es menos usual.(9) Los estudios parasitarios fueron negativos y las biopsias dérmicas sugerían reacción a medicamentos y linfadenopatía dermatopática. La citometría de flujo alejó la sospecha de neoplasias sistémicas o de localización dérmica. $(10,11,12)$ Se le retiró todos los medicamentos, los síntomas persistieron y empeoraron haciendo menos probable la causa medicamentosa pero no descartada totalmente debido a que paciente recibía warfarina por un largo periodo y el cual podría asociarse a eosinofilia y a SH ya sea de manera inmediata, días e incluso meses después de haber tomado dicho medicamento; además, la remisión de la eosinofilia medicamentosa puede durar semanas a meses. $(13,14)$

En cuanto a alergias y enfermedades autoinmunes, el paciente no tenía antecedente ni historial clínico compatible 


\begin{tabular}{|c|c|c|c|c|c|c|c|c|c|c|}
\hline $\mathrm{N}^{\circ}$ de días* & -301 & -116 & -83 & -73 & -38 & -30 & -10 & 0 & +8 & +9 \\
\hline $\mathrm{Hb}(\mathrm{g} / \mathrm{dl})$ & 14,1 & 16,2 & 16,6 & 15,2 & 16,9 & 15,8 & 13,3 & 13,2 & 14,0 & 13,9 \\
\hline Leucocitos $/ \mathrm{mm}^{3}$ & 11690 & 11750 & 5480 & 10800 & 9860 & 13340 & 11980 & 12200 & 10970 & 16370 \\
\hline$\%$ eosinófilos & 24 & 27 & 0 & 6 & 20 & 20 & 25 & 32 & 0 & 0 \\
\hline $\mathrm{N}^{\circ}$ de eosinófilos $/ \mathrm{mm}^{3}$ & 2805 & 3172 & 0 & 648 & 1972 & 2668 & 2995 & 3904 & 0 & 0 \\
\hline
\end{tabular}

Número de días respecto del día de ingreso (0).

\begin{tabular}{|c|c|c|c|}
\hline Etiología / severidad & Leve & Moderado & Severo \\
\hline Infeccioso & Enfermedades parasitarias & $\begin{array}{l}\text { Enfermedades parasitarias, } \\
\text { fasciolasis }\end{array}$ & $\begin{array}{l}\text { Toxocara cani o cati, áscaris, } \\
\text { trichina, estrongilodiasis }\end{array}$ \\
\hline Alergias & $\begin{array}{l}\text { Rinitis alérgica, Atopia, asma } \\
\text { extrínseca, enfermedades } \\
\text { dérmicas, Enfs. pulmonares } \\
\text { ocupacionales }\end{array}$ & Asma intrínseca & \\
\hline Medicamentos & Reacción a drogas & Reacción a drogas & Reacción a drogas \\
\hline $\begin{array}{l}\text { Hematlógicos } \\
\text { Neoplásicos }\end{array}$ & Síndromes mieloproliferativos & $\begin{array}{l}\text { Síndromes mieloproliferativos, } \\
\text { mastocitosis }\end{array}$ & Leucemia eosinofílica \\
\hline Inmunológicas & Estado de inmunodeficiencia & Poliarteritis nodosa & Poliarteritis nodosa \\
\hline Otros & $\begin{array}{l}\text { Diálisis de largo tiempo, } \\
\text { radioterapia }\end{array}$ & Síndrome hipereosinofílico & Síndrome hipereosinofílico \\
\hline
\end{tabular}

Adaptado de las ref.10

con atopias, rinitis, asma, ni estigmas de enfermedad autoinmune. Se procedió luego a descartar linfoma cutáneo de células $\mathrm{T}$ así como síndrome de Sézary, realizándose nueva biopsia de piel que concluyeron como negativos a neoplasia. La citometría de aspirado de médula ósea estudio y el genético en busca de la aberración del gen FIP1L1/ PDGFRA descartaron toda posibilidad de neoplasia (15, 16).

Habiéndose descartado la mayoría de etiologías asociadas se catalogó como SH con compromiso dérmico, confirmado por la biopsia de piel.

Se hizo diagnóstico de $\mathrm{SH}$ en base a los siguientes criterios: hipereosinofilia (eosinófilos $>1500$ células $/ \mathrm{mm}^{3}$ ) persistente y documentada en dos ocasiones por espacio de un mes, confirmación patológica de hipereosinofilia tisular, evidencia de daño o disfunción de órgano mediado por eosinófilos y exclusión de otras causas potenciales que podrían explicar dicha eosinofilia. (1)

El SH es una entidad poco frecuente que puede tomar una evolución desde autolimitada en la mayoría de los casos o ser muy severa y progresiva con infiltración de órganos conllevando a una alta mortalidad. La patogénesis abarca desde la clonalidad a nivel de células precursoras hematopoyéticas hasta presentar una respuesta cíclica persistente que hacen perdurar y aumentar la sobrevida y acción de los eosinófilos mediado por IL-5, IL-1, IL-3, IL-4,
FNT-alfa, células T, citoquinas, quimiocinas, leucotrienos y mastocitos.

Laclasificación estábasada en tres grandes grupos:(10,15,16) - Primaria: la alteración es clonal a nivel medular en la célula madre, que en la mayoría se han detectado aberraciones cromosómicas y la más frecuente se encuentra a nivel de cromosoma 4q12 donde se presenta la fusión de dos genes: FIP1L1 (Fip1-Like1) y PDGFR alfa (platelet-derived growth factor receptor alpha) de importancia clínica ya que esta entidad responde a inhibidores de tirosin-kinasa como imatinib.

-Secundaria: la alteración por respuesta de un agente infeccioso, neoplásico, fármacos, alérgico que causa compromiso eosinofílico y que perpetúa la respuesta inflamatoria disminuyendo la apoptosis y aumentado las citosinas y otros factores inflamatorios y proinflamatorios. - Idiopática: a pesar de los estudios y descartando la patología primarias y secundarias no se llega a filiar la etiología quedando como SH idiopático.

Ciertas variantes de $\mathrm{SH}$ (aquellas asociadas con las aberraciones en el gen de los receptores alfa y beta del factor de crecimiento derivado de las plaquetas (PDGFRA, PDGFRB) ocurren casi exclusivamente en los hombres, mientras que otras como SH-L (variante linfocítica) y SH de etiología desconocida parecen estar distribuidos equitativamente en ambos sexos. $(5,6)$ Las manifestaciones 
clínicas son variables y dependen del órgano afectado, y las más frecuentes son las manifestaciones cutáneas: $(11,17)$. Cuadro 3.

El compromiso cardíaco es la principal causa de morbilidad y en décadas pasadas de mortalidad del SH. Se presenta con una frecuencia alrededor del $50 \%$ de los pacientes con este síndrome. El riesgo de desarrollar enfermedad cardíaca no se relaciona con la magnitud ni con la duración de la eosinofilia. Se presenta con mayor frecuencia en pacientes de sexo masculino, con un fenotipo HLA-Bw44, que presentan esplenomegalia, trombocitopenia, incremento en los niveles de vitamina B12, eosinófilos hipogranulares o vacuolados y precursores mieloides. El daño cardíaco es variable, pudiendo evolucionar desde una necrosis temprana a una subsecuente trombosis y fibrosis. Los hallazgos cardíacos típicos consisten en fibrosis endomiocárdica y trombosis mural, más frecuente a nivel de las puntas de ambos ventrículos. La trombosis puede extenderse a los tractos de salida de las válvulas auriculoventriculares, produciendo insuficiencia valvular. La insuficiencia cardíaca congestiva puede ser el resultado de las anomalías valvulares o de la fibrosis endomiocárdica o de ambas. Los pacientes con $\mathrm{SH}$ con compromiso cardíaco suelen presentarse en los estadios tardíos, trombótico y fibrótico.
Las manifestaciones clínicas incluyen: disnea, dolor torácico, insuficiencia cardíaca congestiva, insuficiencia mitral y cardiomegalia. El ECG puede evidenciar arritmias, inversión de ondas T. El ecocardiograma bidimensional detecta anomalías en el $50 \%$ de los pacientes y las alteraciones varían según el estadio en el que se encuentren los pacientes, no encontrándose hallazgos patológicos en la fase necrótica. (20)

Nuestro paciente tenía fibrilación auricular e insuficiencia cardiaca congestiva que podrían ser explicables por las comorbilidades que presentaba: diabetes Mellitus de larga evolución, falla cardiaca previa como manifestación de cardiopatía isquémica o por cardioangioesclerosis. En este contexto no se podría descartar la posibilidad de infiltración cardiaca por eosinófilos como parte del SH teniendo en cuenta la frecuente afectación del corazón en este síndrome. Esto último requería de una biopsia cardiaca pero no era práctico para el manejo del paciente.

Nuestro paciente con diagnóstico de síndorme hipereosinofílico idiopático con compromiso dérmico fue tratado con prednisona e hidroxiurea, consiguiéndose una remisión completa de la eosinofilia, así como mejoría progresiva de las lesiones dérmicas durante el primer mes de tratamiento.

Cuadro 3. Síndrome hipereosinofílico. Manifestaciones clínicas

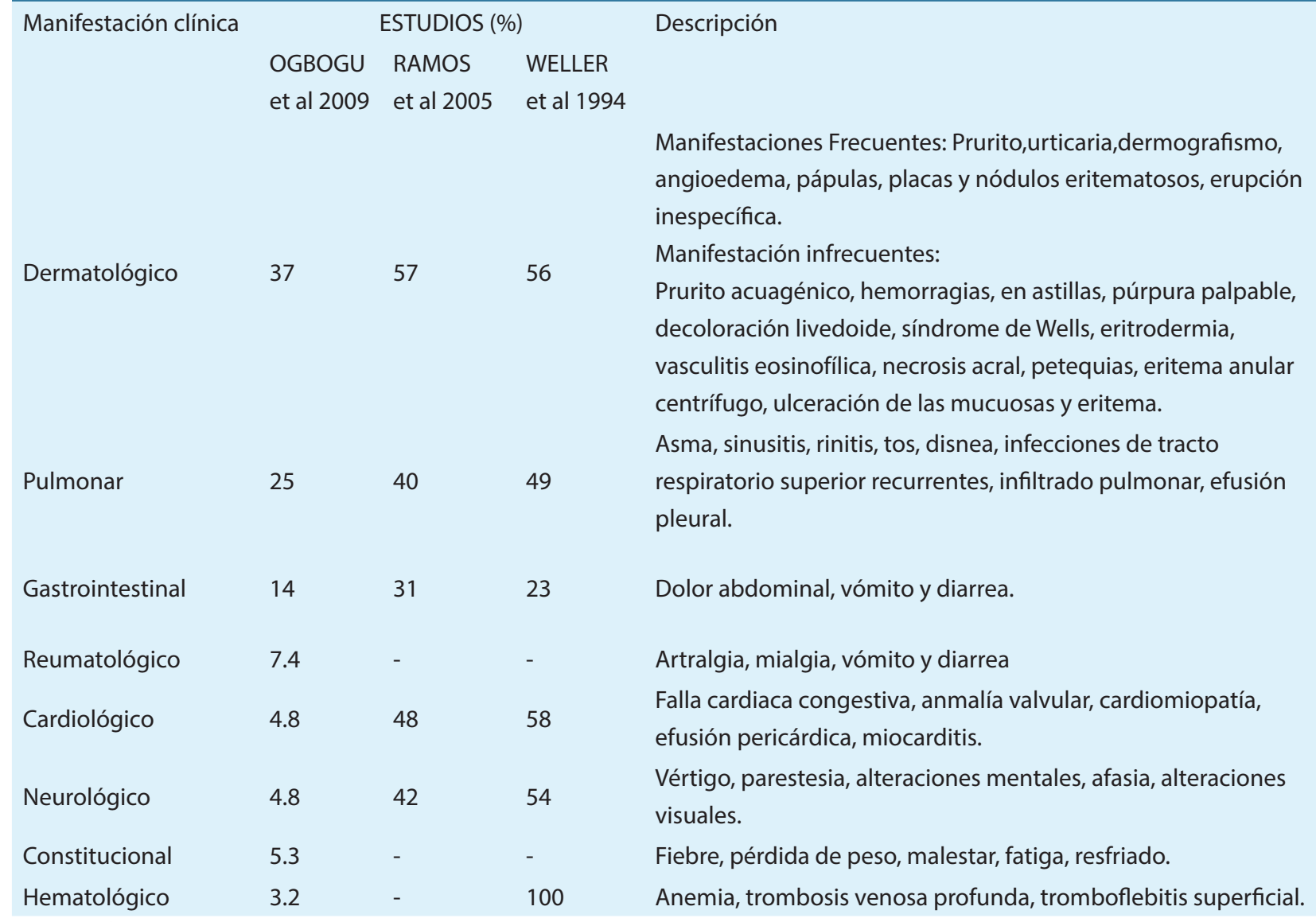

*Adapted from a table in Ref. $(5,19$, 


\section{REFERENCIAS BIBLIOGRÁFICAS}

1. Heung R. Hypereosinophilic syndrome. Allergy Asthma Proc. 2017;38:78-8.

2. Crane MM, Chang CM, Kobayashi MG, Weller PF. Incidence of myeloproliferative hypereosinophilic syndrome in the United States and an estimate of all hypereosinophilic syndrome incidence. J Allergy Clin Immunol. 2010; 126: 179-81.

3. Farruggia $P$, D'Angelo $P$, Acquaviva A, Trizzino A, Tucci F, Cilloni D, et al. Hyperosinophilic syndrome in childhood: Clinical and molecular features of two cases. Pediatr Hematol Oncol. 2009; 26(3): 129-135.

4. Rapanotti MC, Caruso R, Ammatuna E, Zaza S, Trotta L, Divona $M$, et al. Molecular characterization of paediatric idiopathic hypereosinophilia. Br J Haematol. 2010 Dec; 151(5):440-6. doi: 10.1111/j.1365-2141.2010.08394.x. Epub 2010 Oct 19.

5. Ogbogu PU, Bochner BS, Butterfield JH, Gleich GJ, HussMarp J, Kahn JE, et al. Hypereosinophilic syndrome: a multicenter, retrospective analysis of clinical characteristics and response to therapy. J Allergy Clin Immunol. 2009 Dec;124(6):1319-25.e3. doi: 10.1016/j.jaci.2009.09.022.

6. Cheah CY, Burbury K, Apperley JF, Huguet F, Pitini V, Gardembas $M$, et al. Patients with myeloid malignancies bearing PDGFRB fusion genes achieve durable long-term remissions with imatinib. Blood. 2014 Jun 5;123(23):3574-7. doi: 10.1182/ blood-2014-02-555607. Epub 2014 Mar 31.

7. Marcos, LA, Terashima, A, Leguia, G, Canales, M, Espinoza, JR, Gotuzzo E. La infección por fasciola hepática en el Perú: una enfermedad emergente. Rev Gastroenterol Peru, 2007;27(4), 389396.

8. José R. Espinoza JR, Terashima A, Herrera-Velit P, Marcos LA. Fasciolasis humana y animal en el Perú: impacto en la economía de las zonas endémicas. Rev Peru Med Exp Salud Publica. 2010; 27(4): 604-12.

9. Sundaramurthi VL, Prabhavathy D, Somasundaram SV, Wahab AJ. Hypereosinophilic syndrome: cutaneous involvement as the sole manifestation. Indian J Dermatol. 2011 Jan;56(1):107-9. doi: $10.4103 / 0019-5154.77570$.
10. Brigden ML. A practical workup for eosinophilia. Postgraduate Medicine. 1999;105 (3):193-210, DOI: 10.3810/pgm.1999.03.638

11. Noh HR, Magpantay GG. Hypereosinophilic syndrome. Allergy Asthma Proc 2017; 38:78-81.

12. Hsieh, Fred H. Hypereosinophilic syndrome. Annals of Allergy, Asthma \& Immunology. 2014;112(6):484-488.

13. Curtis CD, Ogbogu PU. Evaluation and differential diagnosis of persistent marked eosinophilia. Immunol Allergy Clin North Am. 2015:35(3)387-402.

14. Hall D, Link K. Eosinophilia associated with coumadin. N Engl J Med. 1981 Mar 19;304(12):732-3.

15. Gotlib J.World Health Organization-defined eosinophilic disorders: 2017 update on diagnosis, risk stratification, and management. Am J Hematol. 2017 Nov;92(11):1243-1259. doi: 10.1002/ ajh.24880.

16. Dispenza MC, Bochner BS. Diagnosis and novel approaches to the treatment of hypereosinophilic syndromes. Curr Hematol Malig Rep. 2018;13(3):191-201. doi:10.1007/s11899-018-0448-8

17. Leiferman KM, Gleich GJ, Peters MS. Dermatologic manifestations of the hypereosinophilic syndromes. Immunol Allergy Clin North Am. 2007 Aug;27(3):415-41.

18. Kahn JE, Groh M, Lefèvre G. (A critical appraisal of) Classification of hypereosinophilic disorders. Front Med (Lausanne). 2017 Dec 5;4:216. doi: 10.3389/fmed.2017.00216. eCollection 2017.

19. Ramos Casal M, García Carrasco M, Gómez de Salazar J R, Calvo Alen J, Front Franco J. Enfermedades autoinmunes sistémicas y Reumatológicas. Madrid: Masson, 2005. Capítulo 46, Fascitis eosinofílica; pp. 619-630.

20. Mankad R, Bonnichsen C, Mankad S. Hypereosinophilic syndrome: cardiac diagnosis and management. Heart. 2016 Jan;102(2):100-6. doi: 10.1136/heartjnl-2015-307959. Epub 2015 Nov 13.

CORRESPONDENCIA:

hectorhuayhuaguevara@gmail.com

Fecha de recepción: 12-01-2020.

Fecha de aceptación: 09-03-2020. 